\title{
"Yo llegué a conseguir dónde vivir". \\ Prácticas de lectura en el contexto del desplazamiento forzado: \\ un estudio de caso
}

\author{
"I have arrived to find a place to live" \\ Practice readings regarding forced displacement: a case study
}

Marcela Chapetón*

Resumen

Este artículo sintetiza los resultados de la investigación “Fomentando resiliencia: un espacio para la lectura fuera del aula de clase" desarrollada dentro del marco del desplazamiento forzado en Colombia. El proyecto se proponía documentar, observar y analizar las respuestas dadas por adultos en situación de desplazamiento durante encuentros de lectura, y promover la lectura como un recurso para construir resiliencia a través de experiencias dialógicas. Como resultado de la investigación, el artículo presenta tres categorías principales: 1) los aspectos sociales críticos que emergieron a partir de las experiencias dialógicas, 2) los factores resilientes presentes al enfrentar situaciones de adversidad, y 3 ) los resultados del proceso de resiliencia.

\section{Palabras clave:}

Prácticas de lectura, población en situación de desplazamiento, factores resilientes, resiliencia como proceso de construcción.

\section{Abstract}

This article provides a summary of the results of the research "Fosterimg Resiliency: A space for reading beyond the classroom boundaries" carried out in the context of forced displacement in Colombia. The main purposes of this case study research was to document, observe, and analyze the responses given by five adults in situation of displacement during the reading sessions and to promote reading as a resource in order building resiliency through dialogic experiences. As a result of this research, this article presents three main findings: 1) the social issues that emerged as critical during the dialogic experiences, 2) the resiliency factors present when dealing with adversity, and 3) the results of the resiliency-building process.

Key words:

Reading practices, adults in situations of displacement, resiliency factors, resiliency as a building process.

Artículo recibido el 27 de mayo de 2007 y aprobado el 31 de octubre de 2007

* Profesora del Departamento de Lenguas, Facultad de Humanidades de la Universidad Pedagógica Nacional. Magíster en Lingüística Aplicada de la Universidad Distrital. Estudiante de doctorado en la Universidad de Barcelona, España. cchapeton@pedagogica.edu.co 
Un esfuerzo fundamental de la educación es la liberación del hombre, y esta liberación empieza en la medida en que el hombre reflexiona sobre sí y sobre su condición en el mundo.

Paulo Freire (1985, p. 57)

Cuando el hombre comprende su realidad, puede plantearse hipótesis frente al desafío de esa realidad y buscar las soluciones. Así puede transformarla.

Paulo Freire (1985, p. 68)

\section{Presentación}

En este documento se expone una síntesis de los resultados de la investigación interdisciplinar "Fomentando resiliencia: un espacio para la lectura fuera del aula de clase"1 desarrollada dentro del marco del desplazamiento forzado en Colombia. A partir de una concepción sobre la lectura como una práctica social situada y definida en este estudio desde la perspectiva sociocultural, transaccional y crítica $^{2}$, se creó un club de lectores en la Unidad de Atención Integral a Población Desplazada en Bogotá.

Los objetivos específicos de este estudio pretendían desarrollar conocimiento acerca del tipo de respuestas dadas por los adultos en situación de desplazamiento, mediante las interacciones dialógicas que se dieron durante su participación en las sesiones del club de lectura, e identificar formas en las cuales esas respuestas a la lectura y a través del diálogo pueden contribuir en el establecimiento de mecanismos para solucionar los problemas más inmediatos que las familias en situación de desplazamiento encuentran en su diario vivir.

En esta perspectiva, considero que desarrollar investigación en el campo de respuestas a la lectura es crucial puesto que puede contribuir a la educación de los sujetos como lectores sociales en tres formas importantes: primero, el rol que la lectura cumple

1 Esta investigación se titula originalmente "Fostering Resiliency: A way to share literate voices beyond the classroom bounds" y fue financiada por Colciencias y la Organización Internacional para las Migraciones, OIM durante 2003 y 2004.

2 Para abordar en profundidad los planteaminetos y constructos teóricos, la concepción de lectura que constituye la base fundamental de este estudio y la naturaleza del club de lectores véase Chapetón, M. (2005). Creating reading clubs that foster resiliency: Theoretical foundations. Folios, 21 pp. 3-16. en el desarrollo personal y social del sujeto. Segundo, reconociendo que el significado se construye socialmente, considero que el diálogo y la discusión son temas de gran valor dentro de una comunidad que comparte experiencias y características socioculturales similares. Tercero, la importancia de crear espacios para la libre expresión, donde la población pueda compartir ideas, opiniones, emociones, temores, sueños, sentimientos y todo aquello que se genere de la interacción transaccional entre los lectores, el texto y el contexto, permite profundizar y abordar las realidades de una manera crítica y reflexiva que empodera al sujeto para construir, de manera conjunta y social, alternativas de mejoramiento de esa realidad.

En un nivel más específico, esta investigación buscaba responder las siguientes preguntas:

- ¿Cómo los adultos en situación de desplazamiento construyen resiliencia mediante las transacciones dialógicas que se dan en las sesiones del club de lectura?

- ¿Qué tipo de factores de adversidad identifican los adultos desplazados en las interacciones sociales generadas en el club de lectura?

- ¿Qué tipo de resultados de la resiliencia como proceso son revelados en las declaraciones de los adultos en situación de desplazamiento?

Las poblaciones en situación de desplazamiento son las víctimas directamente más afectadas por el conflicto armado en Colombia. Esta población forzada a abandonar su casa, su cultura y sus costumbres, se ve enfrentada a situaciones desconocidas y deben superar un gran número de problemáticas y necesidades. Esta comunidad tiene derecho a recibir protección y apoyo del Estado y necesita además, del apoyo social de los ciudadanos para encontrar alternativas de solución a esas problemáticas.

Programas alternos educativos, a través de trabajo social en red, pueden constituirse como una oportunidad para estudiar, analizar y comprender esas necesidades. Programas como los encuentros de lectura, creados desde la Asociación Colombiana de Lectura (Asolectura), los Clubes de Lectores y adaptados para la red de Solidaridad Social en la Unidad de Atención Integral a Población Des- 
plazada, permiten a esta población compartir sus experiencias de vida, sus problemáticas actuales, y los habilita, como comunidad, para construir un ambiente resiliente que permita pensar en formas de transformar sus realidades y superar la crisis causada por el conflicto armado. Así, después de haber recibido un entrenamiento como Ayudante de Clubes de Lectores, ofrecido por Asolectura me ofrecí como voluntaria en la Unidad de Atención Integral al Desplazado en Bogotá para crear allí una comunidad de lectores del mundo y de los diferentes textos que leíamos en cada sesión 3 .

Para el desarrollo de este estudio, la metodología de la investigación se asumió desde un enfoque cualitativo y, enmarcada dentro del diseño de caso de estudio y observación participativa, la creación del club de lectores contó con el apoyo de la Asociación Colombiana de Lectura y la Unidad de Atención Integral al Desplazado (UAID) en Bogotá, la cual forma parte de la Red de Solidaridad Social. La UAID es un espacio de coordinación interinstitucional que brinda orientación a la población en situación de desplazamiento sobre las acciones y programas que ofrece el Estado y el distrito en beneficio de ellos. La Unidad recibe apoyo de varias entidades como la Secretaría de Gobierno, Misión Bogotá y la Red de Solidaridad Social, con las cuales trabaja de manera coordinada.

Una de las áreas de trabajo en la UAID consiste en la elaboración de talleres y capacitación en desarrollo humano. Su principal objetivo es ofrecer herramientas prácticas que apoyen el proceso de integración a la ciudad. Los talleres están dirigidos a fortalecer sus potencialidades, fomentar una participación activa y responsable en el ámbito político y recuperar la esperanza y dignidad. Un equipo de voluntarios con multiplicidad de profesiones $y$ ocupaciones permite el intercambio permanente de experiencias y conocimientos.

Los sujetos participantes en el club de lectores son parte de las poblaciones en situación de des-

3 El anexo 1 presenta un resumen de los textos y cuentos cortos que se leyeron durante el desarrollo de las sesiones del club de lectores en la Unidad de Atención Integral al Desplazado, Bogotá. plazamiento que llegan a Bogotá después de haber sido forzadas a abandonar sus viviendas, costumbres, tradiciones y familias. En este club de lectores participaron alrededor de ochenta adultos, hombres y mujeres, población no homogénea originaria de diversas regiones del país, como la Guajira, Chocó, Tolima, Huila, santanderes, la Costa, los Llanos, Antioquia, Cundinamarca y el sur del país. Estas poblaciones con distintos niveles de educación diferentes etnias y (afrocolombianos, indígenas y campesinos) deben enfrentar situaciones precarias en términos de salud, vivienda, educación y alimentación una vez llegan a una ciudad que desconocen. Cinco mujeres en situación de desplazamiento fueron escogidas aleatoriamente para conformar el caso de estudio para esta investigación.

El proceso sistemático de recolección de datos se llevó a cabo durante las catorce sesiones de encuentros de lectura, con un enfoque hacia las respuestas estéticas 4 y el diálogo generado entre los lectores. La lectura con un propósito estético, pertinente para este estudio, requerirá que el lector preste más atención a los aspectos afectivos, a "vivir a través" de lo que está siendo creado durante la lectura, a la mezcla de sensaciones, sentimientos, imágenes e ideas que estructuran la experiencia de leer. Tanto para Freire (1985) como para Rosenblatt (2002), el acto de leer implica siempre interpretación, percepción crítica y "reescritura" de lo leído, es decir de transformarlo a través de nuestra práctica consciente, de la reflexión personal y colectiva de la realidad, del texto.

En un plano más operativo, se emplearon diferentes fuentes y técnicas para la recolección de datos. Los instrumentos de primer orden fueron: notas de campo, entrevista y grabación de audio de las sesiones para su posterior transcripción. Como instrumentos de segundo orden se diligenciaron

4 Rosenblatt (2002) distingue dos tipos de lectura: la eferente (relacionada con la búsqueda de información en el texto para su posterior utilización) y la estética la cual destaca la importancia de la respuesta del lector en su transacción con el texto y el conjunto de experiencias sobre las cuales reflexionar durante el disfrute de la lectura de un cuento, poema u obra literaria. El lector principalmente hace uso de experiencias pasadas con la vida y con el lenguaje para interpretar el significado de las palabras impresas, y es posible ver cómo, a través de esas palabras reorganiza la experiencia pasada para lograr una nueva interpretación. 
cuestionarios de información personal y planillas de asistencia. Los diferentes instrumentos utilizados sirvieron para triangular, validar y verificar la información colectada, y fueron utilizados con previo consentimiento de los participantes y garantizando la reserva de su identidad.

El proceso de análisis e interpretación de datos cualitativos estuvo en permanente proceso de confrontación y comparación. Posteriormente se determinaron temas emergentes del estudio, que resultaron en categorías y subcategorías. Los procedimientos de codificación y categorización han sido iluminados desde la teoría cualitativa de investigación (Hubbard y Millar, 1999; Cohen y Manion, 1995; Merriam, 1998; Strauss y Corbin, 1990).

\section{Discusión de los resultados}

Las tres categorías resultantes del análisis apuntan a responder cada una de las tres preguntas de investigación expuestas anteriormente. En la tabla 1 se sintetizan las categorías y subcategorías emergentes.

La primera categoría presenta el contenido de las frases declarativas que emergieron de las interacciones dialógicas con los textos y con los otros participantes. Esta categoría describe las estrategias que los lectores adultos en situación de desplazamiento utilizaron para enfrentar situaciones de adversidad. El diferente bagaje sociocultural de los participantes y sus experiencias de vida, contribuyeron a que en

5 De acuerdo con Henderson y Milstein (2003), la resiliencia es una nueva perspectiva que ha emergido de ciencias como la psiquiatría, psicología y sociología para referirse a la forma como niños y adultos se sobreponen al estrés, el trauma y el riesgo en sus vidas. La idea de resiliencia también se refiere al hecho de que las personas pueden sobreponerse a las experiencias negativas e incluso fortalecerse en el proceso de superaración. La resiliencia es una característica que varía en cada persona y que puede crecer o declinar con el tiempo; Henderson y Milstein (2003, p. 27-30) describen el perfil de una persona resiliente y listan una serie de factores protectores internos y ambientales que mitigan el impacto de las situaciones de adversidad. Aldo Melillo (2001) explica que el concepto de resiliencia alude a la facultad que tiene un individuo 0 una comunidad de recuperarse, sobreponerse a la adversidad y finalmente transformarse. El autor propone destacar la utilidad de la aplicación del concepto de resiliencia en las múltiples acciones sociales, sanitarias y educativas que podrían adoptarse para dar soluciones globales a diversos problemas incluyendo el empobrecimiento y la exclusión, promovidas desde la economía o desde la política. las sesiones del club de lectura se generaran transacciones dialógicas que les permitieron leer el mundo de una manera crítica y hacer conexiones entre el texto leído y sus propias realidades. Los participantes encontraron un espacio para reflexionar acerca de la sociedad y su lugar en ella, siendo esta reflexión el primer paso en el proceso de construcción de resiliencia.

\section{Tabla 1}

\begin{tabular}{|c|c|}
\hline $\begin{array}{l}\text { 1. Interacciones } \\
\text { dialógicas que implican } \\
\text { aspectos sociales en } \\
\text { la construcción de } \\
\text { resiliencia } 5 \text {. }\end{array}$ & $\begin{array}{l}\text { Fuertes lazos familiares y trabajo en } \\
\text { equipo en el hogar. } \\
\text { Trabajo comunitario en red. } \\
\text { Acceso a la educación. }\end{array}$ \\
\hline $\begin{array}{l}\text { 2. Factores de } \\
\text { adversidad revelados a } \\
\text { través de interacciones } \\
\text { sociales. }\end{array}$ & $\begin{array}{l}\text { Las relaciones intrafamiliares y los } \\
\text { niños. } \\
\text { El abandono de la tierra. } \\
\text { La falta de confianza en el apoyo } \\
\text { ofrecido por las instituciones } \\
\text { gubernamentales. }\end{array}$ \\
\hline $\begin{array}{l}\text { 3. Aprendiendo de la } \\
\text { experiencia. }\end{array}$ & י \\
\hline
\end{tabular}

La siguiente categoría resultante del análisis está asociada con la segunda pregunta de investigación y describe las situaciones de adversidad que los participantes del club de lectores identificaron como críticas a partir de su interacción. Durante el diálogo generado se evidenciaron factores de adversidad propios de la experiencia del desplazamiento forzado y las maneras como estas adversidades tuvieron un impacto en los participantes y sus familias. El hecho de reconocer el impacto de las adversidades es entendido en este estudio como el segundo paso en el proceso de construcción de resiliencia y se considera además como un elemento crucial que influye en los participantes como individuos resilientes capaces de buscar soluciones a sus problemáticas y transformar sus realidades y la de sus familias.

La tercera y última categoría se refiere al resultado del proceso de resiliencia y describe las fortalezas y el aprendizaje que se generó a partir de la experiencia, el enfrentamiento y superación de adversidades implícitas en el desplazamiento forzado. De acuerdo con Grotberg (2002), en esta última etapa del proceso de resiliencia, es posible valorar lo negativo de la adversidad y transformarla en aprendizaje positivo. 


\section{Interacciones dialógicas que implican aspectos sociales en la construcción de resiliencia}

Las sesiones del club de lectores fueron espacios en los cuales los adultos en situación de desplazamiento encontraron de cierta forma la necesidad existencial de dialogar, escuchar y ser escuchados, y construir significado al reflexionar sobre la realidad de su mundo. Para Freire (2002), el diálogo no puede existir en la ausencia de elementos como el amor, la humildad, la fe en el ser humano y la esperanza. Este tipo de diálogo puede generar pensamiento crítico y posibilitar la comunicación y el entendimiento entre los seres humanos. El contenido de las interacciones dialógicas reveló las maneras como los participantes hacían una lectura del mundo generando conexiones críticas con su situación y su realidad social.

A través de sus declaraciones, se evidenció la responsabilidad que los adultos en situación de desplazamiento sienten para realizar acciones que los ayuden a enfrentar y superar la adversidad. Las estrategias identificadas fueron:

a. La creación de lazos familiares fuertes y trabajo en equipo en el hogar. Aquellas familias que se mantuvieron unidas, donde cada miembro cumplió un papel de apoyo mutuo y donde los lazos familiares se fortalecieron, fueron más exitosas en el momento de enfrentar y superar la adversidad. Elementos como el respeto, la unión, el amor, el diálogo, la cooperación, la toma conjunta de decisiones y la esperanza fueron característicos en los hogares exitosos que se fortalecieron como unidad familiar. En el siguiente ejemplo, tomado de los datos ${ }^{6}$, es posible notar la importancia que los participantes le dieron a la familia como una comunidad que ofrece apoyo a sus miembros y que puede trabajar en equipo para sobrellevar la adversidad y constituirse como una familia resiliente:

En la familia la UNIÓN es fuerza y la UNIÓN es cooperación, [S1 y S3: si es verdad] porque FAMILIA que, FAMILIA que se ROMPE, familia que NUNCA llega a ninguna parte, [S3: Claro porque (no se apoyan?)] hay separación.

6 Véase las convenciones utilizadas para la trascripción en el anexo 2.
S3: se parte (???) y esos lazos no los pueden partir, así es la familia de uno (no sé? unida)

S4: eso es lo que se llama cooperación, COOPERAR, el uno para el uno y el otro para el otro, porque al formar cooperativa, lo que formamos es la FAMILIA, y si no hay unión en la familia pues no hay unión en ninguna parte.

Esta estrategia fomentó los tres factores resilientes que de acuerdo con Grotberg (2002) son "Yo tengo" (personas en las cuales confiar y con las que puedo contar), "Yo soy" (un miembro importante en la familia) "Yo puedo" (ofrecer apoyo, ayuda, soluciones, puedo valorar y respetar a los otros).

b. El trabajo comunitario en red emergió como parte de las interacciones dialógicas revelando la importancia dada por los participantes al afecto, la unión y el apoyo comunitario como condiciones que deben estar presentes para superar la crisis, reconociendo los beneficios del trabajo en equipo como grupo y como comunidad:

S1: pues a mí me parece que uno muchas veces no necesita ¿sí?, del gobierno para hacer cosas sino de la comunidad, del entusiasmo que uno mismo puede como comunidad dar y vea, se pueden lograr MUchas cosas cuando hay.../

\section{S2: UNIÓN}

S1: si cuando hay unión entre las comunidades sí (.) cuando hay colaboración.

Se evidenció además el hecho de poder conversar con otras personas que han sufrido experiencias similares encontrando un sentido de equidad e identidad con otros. También, el poder compartir sus preocupaciones y necesidades y, como resultado de esa interacción, encontrar posibles soluciones a esos problemas comunes, les dio la posibilidad de sentirse útiles para otros que habían vivido experiencias de adversidad similares. Esta estrategia fomentó un ambiente resiliente donde fueron visibles nuevamente los factores antes mencionados "yo tengo", "yo soy", "yo puedo".

c. Acceso a la educación. El hecho de proveer oportunidades de acceso a la escolaridad fue visto por los adultos participantes como una responsa- 
bilidad para con sus hijos y como una estrategia para tener un mejor futuro y estar preparado para enfrentar y superar situaciones adversas. En su rol de madres, las participantes expresaron su deseo de mejorar las oportunidades de sus hijos por medio de la educación, para evitar de alguna manera que vivieran lo mismo que ellas habían tenido que vivir:

S2: la niña ahorita el año pasado salió de once y la tengo pues, la idea mía era, o es darle estudio, verla superada, que ella se capacite, que no viva lo que uno ha tenido que vivir.

En el contenido de las interacciones dialógicas fue posible identificar un tema controversial y recurrente referido al derecho de los niños a la educación. Aunque en algunos casos se exponía la importancia de que los niños debían trabajar para poder salir adelante, la mayoría de participantes defendía el derecho de los niños a la educación y su deber como madres de apoyarlos y ofrecerles oportunidades de acceso a la escolaridad:

S3: yo creo que el niño debe ser, ser niño, más bien estudiar y aprender.

S2: ...las personas hay que enseñarlas a que trabajen, porque si no las enseñamos, graves, no salen adelante.

S3: Por eso, con la preparación, la preparación es enseñar al niño para cuando tenga su edad, pueda valerse, entonces uno como padre (los apoya y les da educación?).../

\section{Factores de adversidad revelados a través de interacciones sociales}

Los factores de adversidad son entendidos como circunstancias o situaciones riesgosas que afectan al individuo o a una comunidad. Estos factores de riesgo incrementan la vulnerabilidad y reducen la habilidad del individuo (o de la comunidad) para construir resiliencia (Infante, 2002; Kotliarenco, 1997). Grotberg (2002) afirma que los comportamientos resilientes incluyen la identificación de la adversidad y la capacidad de seleccionar el tipo de respuestas o acciones que ayuden a enfrentar y superar la adversidad. En este estudio se identificó que las experiencias adversas estaban relacionadas con tres aspectos fundamentales: cambios en las relaciones intrafamiliares y los niños, abandono de la tierra y falta de confianza en el apoyo ofrecido por las instituciones gubernamentales; cada uno fue reconocido a partir de las interacciones dialógicas definidas previamente para el proceso de construcción de resiliencia.

a. Los cambios al interior del núcleo familiar y los niños. El hecho de vivir en zonas de alto riesgo causó la destrucción de la unidad familiar, pues en muchos de los casos se vivenció la pérdida de seres queridos o miembros de las familias. Por consiguiente, las madres se convirtieron en cabeza de hogar y tuvieron que enfrentar y superar, con sus hijos, las adversidades causadas por la migración forzada. Una de las principales razones de esta migración es el deseo de proteger a los niños, quienes están en alto riesgo de ser forzados a pertenecer activamente a los grupos que lideran el conflicto armado:

A los niños se los hubieran podido llevar, yo dije no, (.) \{llanto\} (.) pero sí, por el bien de ellos, yo no podía seguir en el pueblo, así como estaba, con esos dos niños en riesgo (.) corriendo peligro.

Los niños que viven en un ambiente hostil generado por el conflicto armado son altamente vulnerables a sufrir otro tipo de problemas -acoso sexual, miedo a salir de sus casas, etc.-, lo cual trae diversas consecuencias tales como el abandono de relaciones sociales y la deserción escolar. Estas personas, aparte de desprenderse de su entorno, rutina, hábitos alimenticios y demás actividades, tienen ahora que enfrentar y asumir un espacio nuevo y extraño.

b. El abandono de la tierra. Una de las principales causas del desplazamiento forzado, según CODHES (2000), es el permanente conflicto socioeconómico relacionado con la tenencia territorial. Estas comunidades son forzadas a abandonar sus pertenencias, sus casas o terrenos, y todo su entorno sociocultural con el único fin de proteger sus vidas y las de sus familias. Este hecho necesariamente implica el abandono forzoso de costumbres, estilos de vida, tradiciones, amigos y familiares: 
Yo soy del Tolima, entonces, la tradición en un hogar humilde (.) pero entonces había esa TRADICIÓN que los tamales, que el regalo, que el estrene, e:, a mí me tocó cambiar mis costumbres y habituarme.

Estos cambios abruptos generan, además de alteraciones físicas y mentales, cambios económicos que deterioran el bienestar de las familias. En las sesiones del club de lectores y en las respuestas a la lectura, los participantes expresaron el vacío y la ansiedad de no estar en el lugar al cual se pertenece, su deseo permanente de retornar a casa y su rechazo al conflicto armado y a la realidad que viven:

se encuentra ese vacío de saber que no se está donde se pertenece...

nueva integración para volver a la casa con su familia”

La carta dice que volvemos al campo. \{"la carta" hace referencia a un elemento constitutivo del texto/cuento leído: Zoom\}

A través de su transaccion con el texto, los participantes hicieron una lectura crítica del mundo y de la realidad, revelando sus sentimientos y vivencias al abandonar sus tierras y llegar a una ciudad receptora que desconocen y que, en muchos casos, no está lista para recibirlos.

c. La falta de confianza en el apoyo ofrecido por las instituciones gubernamentales. Los participantes se refirieron repetidas veces, a la falta de apoyo efectivo ofrecido por las instituciones gubernamentales, ya que sus necesidades básicas continuaban siendo desatendidas a corto y largo plazo. Esta falta de apoyo generó una desconfianza en la tan llamada protección de los derechos humanos. Las consecuencias del desplazamiento forzado tienen un gran impacto social y personal en las poblaciones afectadas por este fenómeno; enfrentar y superar estas adversidades se convierte en su realidad diaria.

\section{Aprendiendo de la experiencia: construcción de un futuro de esperanza}

Para este estudio, los participantes se involucraron en interacciones dialógicas en las cuales hicieron una lectura crítica del mundo, de su mundo y de la realidad social implícita en el proceso de construcción de resiliencia. Sus respuestas a la lectura y su comprensión crítica y creadora del mundo y de la palabra los hizo identificarse como individuos resilientes capaces de poner en práctica factores protectores (Henderson y Milstein, 2003) como la iniciativa, la autonomía, la sociabilidad, la introvisión/introspección, la visión positiva del futuro personal y la capacidad de aprendizaje en su búsqueda de caminos para construir un mejor futuro después del desplazamiento.

En el club de lectura, los participantes manifestaron que el hecho de enfrentar situaciones de adversidad los ha fortalecido y los ha hecho reconocer que son capaces de hacer y obtener muchas cosas con el propósito de proteger sus vidas y construir desde la adversidad. Primero, en el proceso de hacer realidad sus sueños, cumplir sus expectativas y como una manera de reaccionar en contra del conflicto armado. Los adultos participantes tuvieron la iniciativa de realizar acciones para enfrentar la adversidad. La iniciativa se constituye como un factor resiliente que de acuerdo con Henderson y Milstein (2003) se manifiesta en la capacidad de emprender acciones y es necesaria para enfrentar y sobreponerse a situaciones de riesgo o adversidad. Los adultos en situación de desplazamiento mostraron, a través de sus interacciones dialógicas, su deseo y voluntad de proteger sus vidas, de perseverar en el proceso de superación de situaciones críticas y su esperanza en recrear y transformar sus realidades. El sentimiento de esperanza es un elemento recurrente en varias de las sesiones del club de lectores puesto que los participantes se refirieron repetidas veces a sus sueños, a su deseo de construir un mejor futuro, lo cual fue visto como un fundamento para dar sentido a sus vidas y a no darse por vencidos. Los adultos en situación de desplazamiento son personas que luchan y tienen la esperanza de aquellos que aún creen y sueñan. La iniciativa, en palabras de Freire, significa expresar, con un verdadero lenguaje, los anhelos, las inquietudes, las reivindicaciones, los sueños, es emprender acciones, es transformar el mundo, es praxis. 
yo creo que todos soñamos y con salir adelante y no quedarnos así. Con que nuestros hijos salgan adelante.../

buscando como más futuro, para los niños, para uno. Nos vinimos para Bogotá a ojo cerrado.

...yo llegué, a conseguir dónde vivir, fui a ubicarle colegio a mis hijos también...

La realización de acciones, como trasladarse a un lugar desconocido, a pesar de todas las consecuencias y buscar y encontrar un lugar donde vivir, alimentación, servicios de salud y educación para ellas y sus hijos, conseguir un trabajo y adaptarse al nuevo ambiente, les ha hecho reconocer que pusieron en práctica y de manera conjunta otras habilidades resilientes como la autonomía, la introspección y la capacidad de relacionarse. Las participantes expresaron el haber fomentado esos factores o habilidades resilientes cuando se vieron en la necesidad de preservar y proteger la vida y los derechos fundamentales propios y de sus familias.

uno cae en una y uno dice que no se qué, que yo no quiero seguir más adelante que todo eso, y verdá, no necesitamos tener muchas cosas (.) menos apegarse a lo que uno tiene, muchas veces uno sale de las cosas porque ay, la casita, mire que allá el pueblito, mire lo que yo tengo, y eso lo hace a uno quedarse ahí, a no pensar uno un poquito más allá sino

[S3: a quedarse] a quedar pegado a las cosas materiales.

El anterior es un ejemplo del proceso de reflexión e introspección, que se pone de manifiesto cuando la participante percibe que algo está mal en el ambiente y analiza su experiencia y su realidad como adulta en situación de desplazamiento. Esta capacidad le permite abordar $y$ valorar diferentes razones $y$, como resultado de su reflexión, decide que la mejor opción es abandonar su casa. Ella reconoce que la situación de adversidad pudo haber minimizado su resolución de tomar acción. Sin embargo, reconoce también que no se necesitan las cosas materiales si el individuo tiene la voluntad y la iniciativa de construir a partir de la adversidad y exhibe su visión posible y positiva de un futuro personal.
Así mismo, las participantes expresaron la importancia de construir comunidad como una estrategia para superar la adversidad; así se exhibe otra característica resiliente que Henderson y Milstein (2003:28) denominan sociabilidad o la capacidad de crear vínculos y relacionarse positivamente con los demás. El hecho de participar voluntaria y activamente en el club de lectores, y estar dispuestas a involucrarse en interacciones dialógicas y sociales, es una clara muestra de su interés por compartir con otros y fomentar dicha habilidad resiliente:

venir uno a: a encontrarse, a: compartir los momentos, las cosas con los demás y como cambiar esos círculos de amistades que uno tiene y aumentar, de pronto aumentar también algunos, abrir unos espacios, dejar una imagen, que lo conozcan y conocer uno, me ha parecido muy importante.

El interés que revelaron las participantes en construir comunidad y ser parte de un grupo social que les permite dar y recibir apoyo, expresarse libremente, escuchar y ser escuchadas, las identifica como individuos resilientes capaces de construir ambientes resilientes en los que es posible enriquecer vínculos sociales; brindar afecto, apoyo y oportunidades de participación significativa, y aprender de la experiencia propia y que otros han tenido durante el proceso de resolución de problemáticas y superación de situaciones adversas.

\section{A manera de conclusión}

A partir de las prácticas de lectura en el contexto del desplazamiento forzado ha sido posible reconocer tres dimensiones analíticas en el proceso de construcción de resiliencia, evidenciado durante la interacción dialógica y las respuestas generadas en el club de lectores desarrollado en la UAID.

Identificar aspectos sociales críticos, reflexionar acerca de ellos y compartir el resultado de las reflexiones con otros hicieron evidente las estrategias utilizadas para enfrentar y sobreponerse a situaciones de adversidad. La creación de lazos familiares fuertes y la realización de trabajo en equipo al interior del núcleo familiar se constituyeron como estrategias principales, junto con el fomento del tra- 
bajo comunitario en red y el acceso a la educación. En su transacción con el texto, su interpretación y su lectura del mundo, los participantes amplían su comprensión de la realidad social y exploran los factores de riesgo implícitos en el desplazamiento forzado. Estos factores aluden principalmente a los cambios en las relaciones intrafamiliares causadas por la pérdida de miembros de la familia, la vulnerabilidad en la que se encuentran los niños, el abandono de la tierra y la falta de confianza en el apoyo ofrecido por las instituciones gubernamentales. Pero como resultado del proceso de enfrentar y superar situaciones adversas, las participantes del club de lectores reconocieron en esta experiencia la posibilidad de poner en práctica factores resilientes como la iniciativa, la sociabilidad, la autonomía y la introspección, demostrando su visión esperanzadora y positiva del futuro personal y el de sus familias.

De acuerdo con el análisis que se ha presentado en este documento, y en concordancia con Manciaux (2003) y Grotberg (2002), la resiliencia no es una mera lista de características para simplemente dar una respuesta a la adversidad, sino un proceso que incorpora aspectos como: la promoción de factores resilientes en el individuo, la familia y la sociedad, la interacción de los factores resilientes ya mencionados, la identificación de la adversidad y el tipo de respuesta apropiado, y la valoración de los resultados de resiliencia, como aprender o beneficiarse de la experiencia.

La naturaleza estética y dialógica del club de lectores permitió que los adultos expresaran y

\section{Bibliografía}

Cohen, Louis y Manion, Lawrence. (1995). Research Methods in Education. Londres: Routledge.

Codhes. (2000). Esta guerra no es nuestra y la estamos perdiendo. Bogotá: Codhes, UNICEF Colombia: Echo.

Chapetón, Marcela. (2005). Creating reading clubs that foster resiliency: Theoretical foundations. Folios, 21,3-16.

Freire, Paulo. (2002). Pedagogy of the Oppressed. 30th anniversary edition. Nueva York: Continuum.

Freire, Paulo. (1985). La importancia de leer y el proceso de liberación. México: Siglo Veintiuno Editores. compartieran sus sentimientos, anhelos, sueños y preocupaciones e hicieran una lectura crítica y comprensiva del mundo, de sus experiencias de vida y de sus realidades. En ese proceso de lectura, Freire (1985) afirma que es posible "escribir y reescribir" el mundo, es decir, transformarlo. Así, la lectura se constituye en una práctica liberadora y transformadora de la realidad.

En suma, la población participante expresó y demostró ser resiliente, capaz de poner en práctica características individuales resilientes para crear un ambiente de apoyo y construir desde la dificultad y soñar con un mejor futuro para ellas y sus hijos. También fue posible observar que el hecho de compartir y explorar experiencias de vida, preocupaciones, reflexiones, perspectivas, expectativas, sueños y puntos de vista de manera dialógica, pueden contribuir en la construcción de un ambiente resiliente al interior de las comunidades, en este caso, de la construida en el club de lectores.

Finalmente, para lograr una mejor comprensión del creciente fenómeno del desplazamiento forzado en nuestro país, se hace necesario, ante todo, y en acuerdo con varios investigadores en esta línea, prestar atención sistemática y comprometida y orientar conjuntamente acciones decididas hacia la prevención y detención del desplazamiento, así como a la reintegración social, política, económica y educativa de estos ciudadanos que han visto sus derechos vulnerados. Es aquí donde el Estado, la comunidad colombiana, los investigadores y los educadores cumplimos un papel determinante.

Grotberg, Edith. (2002). Nuevas tendencias en resiliencia. En: Melillo, A. Resiliencia: descubriendo las propias fortalezas. Buenos Aires: Paidós.

Henderson, Nan y Milstein, Mike. (2003). Resiliencia en la escuela. Barcelona: Paidós.

Hubbard, Ruth y Miller, Brenda. (1999). Living the Questions: A guide for teacher-researchers. York, Maine: Stenhouse Publishers.

Infante, Francisca. (2002). La resiliencia como proceso: una revisión de la literatura reciente. En Melillo, A. Resiliencia: descubriendo las propias fortalezas. Buenos Aires: Paidós. 
Kotliarenco, María Angélica. (1997). Estado del arte en resiliencia. Organización Mundial de la Salud, Fundación Kellog y CEANIM

Manciaux, Michel. (2003). La resiliencia: resistir y rehacerse. Barcelona: Gedisa.

Melillo, Aldo. (2002). Resiliencia: Descubriendo las propias fortalezas. Buenos Aires: Paidós.
Merriam, Sharan. (1998). Qualitative Research and Case Study Applications in Education. San Francisco: Jossey-Bass Publishers.

Rosenblatt, Louise. (2002) Literatura como exploración. México: Fondo de Cultura Económica.

Strauss, Anselm y Corbin, Juliet. (1990). Basics of Qualitative Research. Grounded Theory Procedures and Techniques. Londres: Sage Publications.

\section{Anexo 1 Club de lectores}

\section{Resumen de los textos leídos}

Ni era vaca ni era caballo

En este relato el escritor guajiro Miguel Ángel Jusayú cuenta sus vivencias de niño pastor y su encuentro nada feliz con el mundo del hombre blanco. Dice el autor que aunque su cuento está basado en la realidad, el final dramático y triste es inventado, y con él quería expresar la miseria en que cae el indígena cuando abandona a su gente y sus costumbres y se va a vivir entre los blancos.

Guillermo Jorge Manuel José

Este niño con tantos nombres vive al lado de un ancianato y es amigo de sus moradores, en especial de la señorita Ana Rosa Josefina Isabel, quien ha perdido la memoria. Guillermo Jorge quiere ayudarle a recuperarla y pregunta a los adultos acerca de ella. En el tratamiento sencillo y profundo del tema de la memoria radica la belleza de este relato que transmite el valor de la memoria como principio de identidad personal. De la mano del personaje principal y en su forma de nombrar la palabra "memoria", su manera particular de recoger los recuerdos propios y los de su anciana amiga, nos reconocemos a nosotros mismos como seres arraigados a nuestros recuerdos.

La calle es libre

Bien podría decirse que, como lo menciona el título de esta historia, la calle es libre. De todos. Libre para correr en ella sin temor a ser atropellados por un conductor irracional, libre para los niños, para sus juegos y encuentros, libre para las personas que habitan en su corazón. Pero, la realidad siempre supera las intenciones. Esta historia justamente relata las peripecias de un grupo de niños de un barrio, quienes, preocupados por la falta de espacios públicos para su recreación, se lanzan a la difícil tarea de solicitar al consejo municipal que les construya un parque.

El burrito y la tuna

Los wayúu cuentan que una mañana, un hombre salió con su burro rumbo a Riohacha. Lo venció el cansancio la noche del tercer día y, mientras descansaba apareció el maligno Wanuluu, un hombre sin rostro. El viajero se escondió y el Wanuluu empezó a interrogar y a golpear el burro, pero el animal hizo todo lo posible por resistir y no delatar a su amo. Furioso, el Wanuluu se retiró dejando al burro herido de muerte. En lugar de ayudar al asno o agradecerle su sacrificio, el hombre emprendió el camino de vuelta a la aldea. Allí narró una historia fantástica e hizo creer a la gente que él solo había vencido el Wanuluu.

\section{Zoom}

Cualquier lectura que se le haga a este libro cuenta una anécdota ambiciosa: la aventura del ser humano, la explosión colorida e intimista de sus manifestaciones contrastando con la pequeñez de su hábitat, una nave a la deriva, del tamaño de un átomo perdido en la infinitud del universo. Nos recuerda que por más disparatadas que sean sus fantasiosas, son irrisorias comparadas con la magnitud de una galaxia, por poner un ejemplo. Es un libro de pocas palabras y un solo punto, el átomo antes mencionado. Cuadros nítidos, realistas, con colores planos y acertadamente combinados, en una sucesión de zooms, desde los poros en la cresta de un gallo hasta el hondo silencio del universo.

\section{Siete ratones ciegos}

Magistral adaptación de una antigua fábula de la India, cada página hace coincidir la brevedad y precisión del texto con la sobriedad del diseño y el uso del papel recortado. Cada día de la semana sale un ratón diferente a explorar "algo muy raro"; al regresar a casa, el primero afirma que es un pilar; en los días siguientes afirmarán que es una culebra, una lanza, un acantilado, un abanico... cada uno cree poseer la verdad, pero sólo "ve" un fragmento. La ceguera es física y espiritual y los siete no logran ponerse de acuerdo. Siete ratones, siete colores, siete días y siete puertas para aprender a contemplar la unidad en medio del caos fragmentario de las formas. 
La composición

A Pedro le parece que algo está pasando en su mundo, pero las noticias que tiene de ello llegan siempre de lejos, tanto que es difícil relacionarlas con las lágrimas de su mamá o con el día en que un jeep se llevó preso al papá de Daniel y él se quedó como dueño de la tienda. Acompañada de las imágenes impresionantes de Alfonso Ruano, esta breve narración de Antonio Skármeta está impregnada por las distancias que debe cruzar un niño entre su mundo y el mundo adulto que lo circunda. Al final, Pedro recompone el rompecabezas y protege a sus padres de la fiscalización militar, ejerciendo una manera particular de la resistencia.

Voces en el parque

Carlos, su madre y la perra Victoria van de paseo al parque. También Mancha, su padre y el perro Alberto. Los personajes se enfrentarán a los mismos hechos, pero cada cual los vivirá y los contará de una manera deferente. Son cuatro voces, cuatro diferentes puntos de vista a través de los cuales iremos enriqueciendo y completando la historia. Como es costumbre en los relatos de Anthony Brown, la ilustración no es pasiva, dialoga con el texto. Aquí es notable la forma en que nos invita a descubrir innumerables detalles que no son tan obvios y que al reconocerlos -podemos pasar horas y horas mirando- irán ampliando nuestra comprensión.

Un pasito... otro pasito

Nacho le enseñó a Ignacio a caminar mientras le decía: "un pasito y otro pasito"; abuelo y nieto son buenos amigos: juegan, ríen, pasean juntos y Nacho cuenta muchos cuentos a Ignacio. Pero un día enferma y al regresar a casa no es ni la sombra del abuelo maravilloso que solía ser. Entonces, Ignacio lo recupera. Ahora es el pequeño el que dice "Un pasito y otro pasito", hasta que el afecto los reúne de nuevo alrededor del juego y los cuentos.

\section{Choco encuentra una mamá}

Choco es un pequeño pájaro que vive solo y tiene enormes deseos de conseguir una mamá. Sin embargo, esto no le resulta muy fácil. A pesar de tener algo similar con la jirafa, la señora pingüino, la morsa y otras posibles madres, ninguna lo acepta como hijo. Cuando ya el pajarito ha perdido la esperanza de hallar una mamá, encuentra a la señora oso. Y si bien esta no se le parece en nada físicamente, lo convierte en uno más de sus hijos. Un libro que aborda con gran delicadeza los temas de la adopción y de la relación afectiva madre hijo.

Miguel Vicente Pata Caliente

Miguel Vicente vive con su madre en un barrio que rodea a Caracas y trabaja como limpiabotas. Todas las mañanas sale tamboreando en su caja de cepillos y cremas para instalarse en el centro de la ciudad, cerca al congreso. Un día, un señor le cuenta de sus viajes y le regala un libro: Los viajes de Marco Polo. Aunque Miguel no sabe leer ni escribir, guarda el libro como un tesoro. Un clásico de la literatura venezolana del recordado Orlando Araújo.

\section{Cambios}

Después que su padre le dice: "A partir de ahora las cosas van a cambiar" José Kaf, el protagonista, comienza a notar que todas las cosas de la casa cambian: la tetera se transforma en gato, la pantufla en ave, el lavamanos en rostro, el sofá en cocodrilo, el sillón en gorila. Es tan desconcertante la situación que, temeroso de que todo cambie, se mete en su cuarto, cierra la puerta y apaga la luz. Cuando ésta se abre de nuevo, entran sus padres y le presentan a su hermanita recién nacida, quien a partir de ese momento hará que todo cambie en casa, como pronosticó el papá.

Yo puedo

Yo también

Un hermano mayor nos muestra qué siente y piensa frente al deseo de su hermana menor de hacer todo lo que él hace. Aparentemente, él se reafirma frente a la incapacidad de su hermana, pero al final, comprende cuánto lo necesita ella y borra su impaciencia con un gesto amoroso. Las ilustraciones recrean el universo de la infancia, rescatando con sobriedad los momentos de juego que comparten los dos hermanos; su gran aporte es concentrarse en lo esencial de esa relación aparentemente desigual de los dos niños. Se complementa con Yo también. 
El túnel

Un túnel, por lo general, conduce a un sitio muy concreto, pero el de este libro sirve de pasadizo al mundo del inconsciente. Dos hermanos que en nada se parecen, ella porque permanece sola en casa, leyendo y soñando, él porque se la pasa en la calle con los amigos, riendo y jugando fútbol, pelean como todos los hermanos, pero resuelven sus rivalidades en forma atípica, en el mundo imaginario. Lo interesante es que esta teoría, tan compleja al intentar explicarla, es invisible y sencillísima en El túnel, un libro apto para lectores de todas las edades.

El libro de los cochinitos

Tres poemas que hacen un recuento de los diferentes nombres del cerdo, de su educación y de los diferentes tipos de papás que existen, todos ellos representados por cerdos. Al final, el libro presenta, en un lenguaje preciso y agradable, una información de carácter documental en la cual se explica cómo son los cochinitos y un glosario con el origen de las diferentes denominaciones que se le han dado a este animal. Los poemas son rimados, sin llegar al extremo de una métrica obsesiva, y de un delicioso humor.

El libro de los cerdos

La primera página presenta a la familia: en primer plano, el próspero, grande y sonriente señor De la Cerda, flanqueado por sus dos sonrientes hijos, Juan y Simón. Atrás la casa, el jardín y el carro en el garaje: todo muy bonito. Después, los diferentes objetos domésticos se transforman paulatinamente en cabeza de cerdo, hasta llegar al clímax, la metamorfosis total, la contundente aseveración de que "son unos cerdos". Brown realiza esta radiografía, satírica y desmitificadora, de los roles en la familia actual, con magistral habilidad en las técnicas pictóricas, el manejo del color y las referencias culturales.

El cocuyo y la mora

En la historia del enamoramiento -en reversa y a destiempo- entre el cocuyo y la mora, se basa este cuento para explicar la razón de ser de la luz que los cocuyos cargan en sus colas. Bien vale la pena conocer este legado de interpretación y recreación de los fenómenos que nos dona la sabiduría intuitiva de la cultura indígena de nuestros pueblos. La tribu Pemón habita en el sudeste de Venezuela. Las ilustraciones de intenso colorido atraen al lector por su belleza y expresividad.

\title{
Anexo 2
}

\section{Convenciones utilizadas para la transcripción}

\author{
S1, S2, S3, S4, S5 \\ indican las intervenciones de los participantes. \\ MAYÚSCULAS \\ ? \\ : \\ $-$ \\ (.) \\ [] \\ .../ \\ \{\} \\ (???) \\ (palabras?) \\ indican énfasis/subida de tono en la pronunciación de una sílaba o palabra. \\ marca el final de una producción con entonación ascendente. \\ indica alargamiento del sonido que le precede. \\ palabra o emisión inacabada. \\ marca pausa breve en un enunciado. \\ indica pausa media dentro del turno de habla del mismo hablante. \\ indica solapamiento entre producciones o intervenciones. \\ marca interrupción en la producción o intervención. \\ proporcionan información adicional. \\ material ininteligible. \\ señala que se duda acerca de las palabras transcritas.
}

